\title{
An Effective Partial Extraction Method for Mineral Exploration in Areas Covered by Transported Overburden
}

\author{
S.X. TANG*, S.M. MA AND S.Q. HU
}

Institute of Geophysical and Geochemical Exploration, CAGS,

Langfang 065000, China (*correspondence:

tangshixin@igge.cn)

Noncrystalline iron-manganese oxides in soil, under the condition of high temperature and anaerobic enviroment, can transform into magnetic crystalline iron-manganese oxides defined as thermomagnetic component which can be separated by magnetic effect. As a partial extraction method, Soil Thermomagnetic Component Measurement (STCM) is available for detecting surface weak mineral information caused by concealed orebody, which mainly applied in coverage regions where conventional geochemical exploration methods present challenge. Our research showed that STCM was effective for mineral exploration in areas covered by transported overburden. The result of our study carried out at a copper polymetallic mining area in northwestern China is shown in the figure below. Fig.1 shows the concentration of $\mathrm{Cu}, \mathrm{Ag}, \mathrm{Pb}$ and $\mathrm{Zn}$ in three different samples from the surface of concealed orebody. It means from residual sample to soil to thermomagnetic component, the concentration of metallogenic indicator element tends to increase. In addition, our research also shows that STCM is beneficial to estimate mineralization types and buried depth of concealed orebody from the spatial distribution and suits of elements.

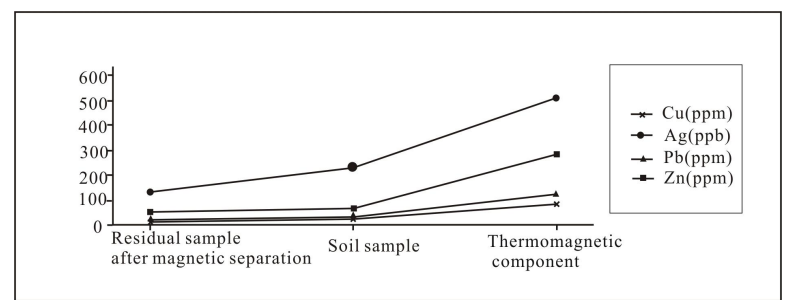

Figure 1: Concentration of three different samples

Noncrystalline Fe-Mn oxides are closely related to various types of ore-forming elements and most of those elements would be hosted by Fe-Mn oxyhydroxides in the soils. And in micropore space of thermomagnetic component, metal particles such as $\mathrm{Au}$ and $\mathrm{Ag}$ and $\mathrm{Zn}$ and $\mathrm{W}$, etc which size range nano to micro are observed by SEM. This discovery provides a microscopic evidence for the mechanism research of STCM. 